\title{
The Psychosocial Ecology of Gun Ownership in the United States: Examining Factors that Affect People's Willingness to Buy or Own Firearms
}

\author{
By Avdi Avdija*
}

\begin{abstract}
This research study examines the effects of environmental factors (e.g., location of residency), psychological factors (e.g., fear of crime, fear of victimization), and social factors (e.g., parents gun ownership status, income, education) on gun ownership and the decision to buy guns in the United States. It also examines the typical reasons for owning firearms, and provides an estimate of firearms in American households. The analyses are based on two data sets: one from a national representative sample of 2568 private gun owners and non-gun owners in the United States, and one from a sample of 317 household representatives in the State of Indiana. The research findings that emerged from this study show that the strongest predictor of gun ownership in the United States is farm-country location of residency, indicating that the respondents who lived in the farm-country were almost 4 times more likely to own guns and 3 times more likely to buy guns compared to other residency locations (e.g., large cities). The second strongest predictor is parents gun ownership status, indicating that if the parents of the respondents owned guns, then they were almost 3 times more likely to own guns and 2 times more likely to buy guns compared to other counterparts. The decision to buy guns is strongly influenced by the veteran status and respondents' race. This study shows that whites own more guns than blacks and Hispanics, but blacks and Hispanics are more willing to buy guns compared to whites. The primary reason for owning guns, on the other hand, is for hunting. Selfdefense comes second, and owning guns for sports is ranked third on the list of reasons. In terms of an estimated number of firearms in American households, this study show that $90.3 \%$ of household reported having at least one firearm in their homes, and $71.2 \%$ of household reported having multiple firearms (6 or more) in their homes.
\end{abstract}

Keywords: Fear of crime, Gun ownership, Protection, Political affiliation, Self-defense, Victimization.

\section{Introduction}

In the United States, the right to "keep and bear arms" is a constitutional right. The U.S. Constitution does not specify what type of guns people can "keep and bear" but, unlike most other countries, this right is protected on a statutory level. Very few countries around the world recognize the right to bear arms; much less protect this right under the umbrella of the supreme law of the land. When it comes to the question, should people be allowed to own or buy guns?, most people lose track, and derail going toward gun violence and casualties that the presence of guns brings to the public - perhaps rightfully so. Nonetheless, gun ownership has two sides of the story, and oftentimes only one side of it is told. Most people fear

\footnotetext{
*Associate Professor of Criminology and Criminal Justice, Indiana State University, USA.
} 
that guns kill people. The assumption is that if you own a gun, you are more likely to use it. That is primarily an inaccurate representation of reality if the argument includes legitimate gun owners. It would be accurate, however, if the argument includes criminals (e.g., gang members, and chronic offenders). To say that "I don't want a gun because I don't want to use it," is the same as to say, "I don't want airbags in my car because I don't want to crash my car." People are afraid that if they own guns, they may hurt themselves. People can also hurt themselves if they own chainsaws, but that doesn't mean that they should get rid of them.

Moreover, a frequently cited reason behind gun ownership is fear of government tyranny or lack of confidence in government (Jiobu and Curry 2001, Chemerinsky 2004). The U.S. Constitution guarantees individual rights. But, it is the government that has the power, and in fact, the potential violator of those rights. If the same entity that can violate those very rights is put in charge of guaranteeing them, then chances are those civil rights will be protected selectively. As George Washington stated that "Government, like a fire, it is a dangerous servant, and a fearful master; never for a moment should it be left to irresponsible action" (David 1997: 71, emphasis added). Even the most tyrannical, dictatorship countries have constitutional guarantees addressing the freedom of speech, the freedom of assembly, and the right to vote, but in practice those are violated by those who carry guns, i.e., the executives and the government agents (e.g., the police, military, and other government security forces), not civilians. After all, it is fear of consequences that keeps people in line (Papachristos et al. 2012). That fear is inflicted by those who have the right to carry guns. Thus, governments do not want to create a balance between those who can inflect fear on others; namely the police and armed civilians. In other words, the government does not want a civilian people to have such ability. Controlling guns, therefore, offers the government the advantage to be the only fear-inflicting entity to maintain control over those less powerful. It is the same government that attempts to violate the very freedom that the constitution guarantees. This research study, thus, examines the reasons why people own firearms in America; examine factors that affect gun ownership, and factors that affect people's willingness or decisions to buy firearms. In the analyses, specific environmental factors (e.g., location of residency), psychological factors (e.g., fear of crime, fear of victimization), and social factors (e.g., parents gun ownership status, income, education, etc.) are included.

\section{The Concept of Self-Defense - The Pro-Gun Argument}

What gives gun ownership a bad reputation is that there is a small percentage of people who abuse this right. Gun ownership is a right, not a privilege. Although a significant number of people buy guns for self-defense (Kleck et al. 2011), they do not actually use them for self-defense. Research shows that most gun owners who buy guns for self-defense use guns to threaten and intimidate others more often than they use for self-defense (Hemonway and Miller 2000). Nonetheless, the majority of gun owners argue that it is better to have them and never have to use them than not have them when you need to defend yourself. Consider the 
argument about whether to wear a seatbelt or not when you are driving. The main purpose of a car seatbelt is to prevent an injury in case of an accident. The assumption is that not all drivers in traffic drive safe. So, wearing a seatbelt is a preventive measure against an unexpected traffic accident that, in many instances, may be caused by someone who might be drunk, under the influence of drugs, etc. Life is a process, and the process of living is like a highway. Living life means sharing common grounds with the good and the bad people. When you get on highway, you don't know who is behind the wheels of other cars. No matter how good your driving is, someone else may cause you to have an accident. Thus, it is better to have a preventive measure in place (i.e., wearing the seatbelt) so that you can minimize injury than not having a preventive measure at all. The same analogy applies to carrying a gun responsibly and solely for protection. For responsible people to carry firearms is the same as for responsible drivers to wear a seatbelt. Lately, there is a skewed public perception about the leading cause of firearm-related death in America, which is a misperception (Morgan et al. 2018). People mistakenly believe that there are more firearm-related deaths than any other causes of death. Research shows that this is simply a misrepresentation of the truth. The leading cause of death in the United States is heart disease, followed by traffic-related deaths, and other health-related issues (Kochanek et al. 2015, Jemal et al. 2005, Mokdad et al. 2004).

Generally speaking, at the individual level, the concept of self-defense, for which most people claim that they own guns for, comes from the necessity to balance powers. The temporal ordering of self-defense puts your actions secondary. That is, the initiator of an attack should not be you; rather he is a perpetrator that has already launched an invasive behavior, harmful enough to warrant an action from you to defend yourself. Furthermore, this means if you do not take actions to defend yourself, you become a victim. Opportunity of an armed criminal makes you a victim. Without initiating an attack, without being invasive, any action you take, in this case constitutes self-defense. Self-defense is a legal defense against those who do you harm (JUSTIA 2018), and is recognized in all Western Countries.

At the society level, the on-going debate about taking away guns can be seen as hurtful to the country. It will weaken the defense in two ways: 1) the physical defense will weaken in case of an invasion (e.g., war), and 2) the psychological weakening of morale ${ }^{1}$, which is even more damaging to the societal than people are comfortable to believe. If people have a strong psychological morale in terms of the feeling of superiority and entitlement to defend themselves, no other country will attempt an invasion because people will put up a fight. Those countries with weaken morale are very quick to take the status of a victim, even when they can successfully defend themselves. This comes as a result of unwillingness to put up a fight for what's rightfully theirs.

People in the United States rightfully believe that they should be able to protect themselves when the situations arise (Dowler 2002, Cohen et al. 2012). Though, the factors which influence individuals to purchase guns in the United States have changed somewhat in recent years, they are influenced by society and

\footnotetext{
${ }^{1}$ See Doherty (1988) on the conceptualization and measurement of psychological morale.
} 
the environment where they live, too often driven by fear, and not necessarily consistent with stated desired outcomes.

\section{The Concept of Self-Defense - The Gun Control Argument}

While high gun ownership overall might diminish victimization for some less serious crimes, from the research perspective, studies show that owners of handguns are actually at an increased level of individual risk for violent crime (van Kesteren 2014). This can occur for a variety of reasons. Guns can lead people to feel more secure, or even give them the illusion of invincibility and so they may, consciously or unconsciously, not pay as much attention to their surroundings or take note of situational factors that people without guns employ to keep themselves safe. Thus, they may take more risks. For instance, they may be more likely to assume they are protected to walk alone on a dark or uninhabited street. Or spurred by confidence from a gun, they may even inject themselves into a situation in which there is potential danger, or escalate an argument (e.g., engage in forms of road rage) which might not have happened if they were unarmed (Hemenway and Miller 2006).

Research shows that gun ownership and gun-related assaults are positively correlated (van Kestern 2014). It shows that the presence of guns at home increases the likelihood three to five times higher that a family member will become a victim of homicide (Violence Policy Center 2013, van Kesteren 2014) or commit suicide. This is particularly true for women where the link between gun availability at home and homicides against women has been resolutely linked (van Kesteren 2014). Women are particularly at risk for homicide by guns when they attempt to end an intimate relationship (Hemenway 2013). Moreover, in addition to not providing security from the violence of others, gun ownership also has an alarming impact on self-inflicted gun violence. Half of all suicide deaths in America are committed with a gun, as those who attempt to commit suicide with a gun are more likely to succeed (Hemenway 2013). Conversely, Miller et al. (2006) found that as gun ownership declined, there was a corresponding significant decline in the rate of firearm suicides and overall suicides. This suggests that gun ownership not only puts the owner at greater risk of harm from others, but also it may contribute to greater self-harm rates, primarily due to the easy accessibility of firearms in a moment of depression or panic.

Another argument against gun ownership is that there are people who carry firearms not for protection but desperately waiting for heroic opportunities. This is oftentimes fueled by the media. Certain types of people constantly seek out opportunities to draw attention, in hopes that they will be the ones to stop a mass shooting or prevent a gun-related assault. Research shows that in the past three decades, there were zero mass shooting cases that were stopped by armed citizens (Gilson 2013). 


\section{Relevant Factors that Affect Decisions to Buy or Own Guns}

Some research shows that political commitment can influence a person's likelihood to own a gun. For example, Conservatives and Conservative-leaning individuals are more likely to own guns compared to Liberals and Moderates (Parker et al. 2017, Saad, 2011). People may own guns for their careers (e.g., police, security or armed forced) or might report that they bought a gun for no specific reason (Van Kesteran, 2014). Hunting is a common reason reported for owning guns, as are recreational sports such as target practicing and gun collecting. However, while hunting remained the main reason cited for owning a gun in 1999 (49\%), by 2013 just 32\% reported hunting as their primary purpose in purchasing a gun (Pew Research Center 2013).

Alternately, more and more people cite protection as a reason for obtaining a gun, with $48 \%$ giving that as a reason in 2013 versus $26 \%$ in 1999, and $65 \%$ of women who now own guns have cited protection as their primary reason for owning guns (Pew Research Center 2013, Parker et al. 2017). Gun owners appear to feel less vulnerable with a gun. Van Kesteran (2014) found that people in the United States were more likely than those of other developed countries to cite prevention and protection as their main arguments for owning and carrying guns. Ironically, white people are more likely to cite protection as the primary reason for owning a gun, but blacks, males in particular, are actually much more likely to die from gun homicide (O’Brien et al. 2013).

Kalesan et al. (2016) found that people who reported living in a social gun culture were more likely to own guns than those who did not report living in such gun culture. Social gun cultures were those in which there was a significant peer pressure from friends and families to own guns, and/or in which routine social and family life activities involved guns. Guns seem to be more prominent in the social values of these cultures. This could also explain why gun ownership seems to be higher in certain areas of the country such as the South and the Midwest (Saad 2011). Hemenway (2013) also support the idea that social norms impact gun ownership and gun violence.

What makes gun ownership disturbing is that some segments of the population purchase guns with the intention of participating in illegal acts. One area in which this has been studied more in depth is the area of youth ownership and carrying of arms (Hemenway et al. 1996, Callahan and Rivara 1992). As young people are generally restricted in ownership by law, the stated reasons why they choose to obtain guns frequently differ from the general population. This includes gangs and other youth environments which are more prone to what Hemenway (2013) describes as young men feeling disrespected in social groupings whose norms requires a violent response. These guns are not purchased legally but are generally trafficked or obtained through straw purchasing, where someone legally obtains the gun for the person who is not able to legally purchase it (Kennedy et al. 1996, Cook et al. 2015).

Finally it must be acknowledged that sometimes paranoia and power influence a person's decision to purchase a gun, which legitimately concerns those who are pro-gun control. Given the prevalence of safety and protection as reasons 
why many people choose to purchase and carry a gun, it can be difficult to quantify just when fear crosses the border to paranoia. Hauser and Kleck (2013) argued that while a majority of gun owners cite fear of a crime as the main reason for buying guns, actual gun ownership did not necessarily reduce their fear. This indicates continued underlying apprehension, which in some cases can build to paranoia. Furthermore, Swanson et al. (2015) found that a significant number of people in the United States exhibit impulsive, angry behaviors and meet diagnostic criteria for mental and personality disorders, and yet they own and carry firearms. In addition, the Southern Poverty Law Center identified 1,096 "anti-government" groups active in 2013, a 15\% increase over 2008 numbers (2014). In some cases at least, paranoia, misconceptions and possibly even mental illness are relevant factors in the decision of some citizens to purchase guns. Gun ownership should come with responsibility.

\section{The Present Study}

The current study is rather unique in its nature because it attempts to answer four basic research questions that most people around the globe want to know. Thus, the audience for this research is international. In the United States, the ability to protect one's family, self, and belongings has long been deeply rooted in man's personal belief and self-pride. Buying and owning guns for protective purposes provides the owner a personal sense that, if trouble comes, they do not need to wait or let their family down. Beyond protection, hunting, sport/target practicing, constitutional right, collective purposes, and the media's influence explain why people buy or own guns. But, beyond all of this, there is a sense of pride that comes with gun ownership - a feeling of superiority that changes the culture and mentality whole together. The current study attempts to answer the following research questions:

1. Who is most likely to own guns in the United States? In other words, what factors predict the likelihood that the respondents would report they own guns? This would be answered in a form of descriptive profile of a typical gun owner using a fifteen-variable model.

2. What factors have a statistically significant influence on the decision to buy guns?

3. Why do people buy or own guns? This question addresses the typical reasons as to why people own or buy guns.

4. How many firearms do each household have in the United States? This is a rather difficult question to answer, but the answer will be inferential in nature - generalizing from a sample of 317 households in the State of Indiana that were asked to quantify the number of firearms they have in their homes (see the results section). 
Methodology

Independent Variables

Table 1. Descriptive Statistics for all Variables in the Model $(N=2568)$

\begin{tabular}{|c|c|c|c|c|c|c|}
\hline Variables & Description & Med & Min & Max & $\mathbf{M}$ & SD \\
\hline Age & Measured in continues years & 40 & 18 & 95 & 43.16 & 16.39 \\
\hline Black & $\begin{array}{l}16.7 \% \text { Blacks (coded } 1) \\
83.3 \% \text { other races (coded } 0)\end{array}$ & 0 & 0 & 1 & 0.17 & 0.37 \\
\hline Hispanic & $\begin{array}{l}15.8 \% \text { Hispanics }(\text { coded } 1) \\
84.2 \% \text { other races }(\text { coded } 0)\end{array}$ & 0 & 0 & 1 & 0.16 & 0.36 \\
\hline $\begin{array}{l}\text { White (base } \\
\text { variable) }\end{array}$ & $\begin{array}{l}63.3 \% \text { Whites (coded } 1 * \\
36.7 \% \text { other races (coded } 0)\end{array}$ & 0 & 0 & 1 & 0.64 & 0.47 \\
\hline Married & $\begin{array}{c}57.9 \% \text { Married (coded } 1) \\
\text { 40.8\% Not Married (coded } 0)\end{array}$ & 1 & 0 & 1 & 0.59 & 0.49 \\
\hline Number of Children & Measured in continues numbers & 0 & 0 & 9 & 0.92 & 1.22 \\
\hline Employment & $\begin{array}{l}\text { 75.5\% Employed (coded 1) } \\
23.4 \text { Unemployed (coded } 0)\end{array}$ & 1 & 0 & 1 & 0.76 & 0.42 \\
\hline Education & $\begin{array}{c}\text { Measured from "None" (coded 1) to Graduate } \\
\text { Degree (coded 7) }\end{array}$ & 4 & 1 & 7 & 3.81 & 1.38 \\
\hline Income & $\begin{array}{c}\text { Measured from "Under } \$ 5000 " \text { (coded 1) } \\
\text { To "\$75,000 and up" (coded 8) }\end{array}$ & 5 & 1 & 8 & 5.09 & 1.93 \\
\hline Veteran Status & $\begin{array}{c}14.8 \% \text { were Veterans }(\text { coded } 1) \\
78.4 \% \text { were Non Veterans }(\text { coded } 0)\end{array}$ & 0 & 0 & 1 & 0.16 & 0.36 \\
\hline Parents own Guns & $\begin{array}{c}\text { 56.6\% Parents own guns (coded } 1) \\
\text { 42.3\% Parents do not own guns (coded } 0)\end{array}$ & 1 & 0 & 1 & 0.57 & 0.49 \\
\hline $\begin{array}{l}\text { How Safe in } \\
\text { Neighborhood }\end{array}$ & $\begin{array}{l}\text { Likert Scale from "Very safe" (coded 1) to } \\
\text { "Very unsafe" (coded 4) }\end{array}$ & 1 & 1 & 4 & 1.93 & 0.96 \\
\hline How Safe at Home & $\begin{array}{l}\text { Likert Scale from "Very safe" (coded 1) to } \\
\text { "Very unsafe" (coded 4) }\end{array}$ & 1 & 1 & 4 & 1.49 & 0.74 \\
\hline $\begin{array}{l}\text { Perceived Crime } \\
\text { Level }\end{array}$ & $\begin{array}{l}\text { "Decreasing" (coded 1), "About the same" } \\
\text { (coded 2), "Increasing" (coded 3) }\end{array}$ & 2 & 1 & 3 & 2.14 & 0.50 \\
\hline $\begin{array}{l}\text { Number of People in } \\
\text { House }\end{array}$ & Measured in continues numbers & 2 & 1 & 10 & 2.10 & 0.92 \\
\hline Farm - Country & $\begin{array}{c}17.4 \% \text { Live in Farm/Country (coded } 1) \\
82.6 \% \text { Other Locations (coded } 0)\end{array}$ & 0 & 0 & 1 & 0.17 & 0.37 \\
\hline Small City & $\begin{array}{l}30.3 \% \text { Live in Small City (coded } 1 \text { ) } \\
69.7 \% \text { Other Locations (coded } 0)\end{array}$ & 0 & 0 & 1 & 0.30 & 0.45 \\
\hline Medium City & $\begin{array}{c}\text { 16.4\% Live in Medium Sz. City (coded 1) } \\
\text { 83.4 Other Locations (coded 0) }\end{array}$ & 0 & 0 & 1 & .16 & .37 \\
\hline $\begin{array}{l}\text { Large City (base } \\
\text { variable) }\end{array}$ & $\begin{array}{l}22 \% \text { Live in Large City (coded 1) } \\
78 \% \text { Other Locations (coded } 0 \text { ) }\end{array}$ & 0 & 0 & 1 & .22 & .41 \\
\hline Conservative & $\begin{array}{l}\text { 39.4\% Conservative (coded } 1) \\
51.4 \text { Other political view (coded } 0)\end{array}$ & 0 & 0 & 1 & .43 & .49 \\
\hline Moderate & $\begin{array}{l}27.2 \% \text { Moderate }(\text { coded } 1) \\
63.7 \% \text { Other political view (coded } 0)\end{array}$ & 0 & 0 & 1 & .30 & .45 \\
\hline $\begin{array}{l}\text { Liberal (base } \\
\text { variable) }\end{array}$ & $\begin{array}{c}24.2 \% \text { Liberal (coded } 1) \\
66.6 \% \text { Other political view (coded } 0)\end{array}$ & 0 & 0 & 1 & .27 & .44 \\
\hline
\end{tabular}

Note: The percentages that do not equal to $100 \%$ is due to small percentages for missing data, which are not included in this table. Med stands for medium value, Min for minimum value, Max for maximum value, $M$ for mean value, and $S D$ for standard deviation value. 
The independent variables in this study can be grouped into three main categories. The first category includes the demographic variables (e.g., age, race, education, employment status, marital status, and income). The second category includes variables such as perceived level of crime, neighborhood safety, home safety, number of people in the household, and the location of residency. The third group includes political affiliations. This includes three major political groups: conservatives, liberals, and moderates. As depicted in Table 1, age is measured in continues years, race has been re-coded into dichotomous variables (e.g., dummy variables) with binary response categories, Yes (coded 1) and No (coded 0). For race, "White" is the base category; meaning that all other races are measured against the base category. Marital status, employment, veteran status, and parental gun ownership status are nominal variables with binary (Yes or $\mathrm{No}$ ) response categories, with Yes - coded 1 and $N o$ - coded 0. Education, income, neighborhood safety, home safety, and the perceived level of crime are ordinal variables. Location of the residency has been re-coded into dichotomous variable, with the "Large City" used as the base category. Likewise, the political affiliation has been re-coded dichotomously with Yes/No response categories. For the political affiliation, conservatives and moderates are measured against Liberals, which is used as the base category in this study.

\section{Dependent Variables}

The first two outcome variables in this study are gun ownership and willingness or planning to become a gun owner. Both variables are measured dichotomously with Yes/No response categories. Given that the outcomes of these two dependent variables are binary in nature; multiple logistic regression analysis was deemed the best and most suitable method for analyzing the data. Logistic regression is a form of binomial regression suitable to use for the data when the outcome of the dependent variable has only two categories, ranging from 0 to 1 (Pallant 2007, Menard 2002). The third outcome variables focuses on answering the "Why" question, in reference to the reasons why people own guns. The fourth outcome variable is an estimated number of firearms in the American households. To address the third and fourth outcome variables, the data were analyzed descriptively. The estimated number of guns in the American households as an outcome variable in this study is answered based on the 2018 data set, whereas the first three outcomes are derived from the analysis of the secondary data set (see section below).

\section{Participants and the Data}

The analyses in this study are based on two independent data sources. The first data source comes from a sample of $(n=317)$ representatives of households in the State of Indiana that the author has collected twice a year for a period of seven years (from January of 2012 to December of 2018), and the second data source includes a national representative sample of $(n=2568)$ individuals who owned and did not own guns in the United States. The second data source consists of 
telephone surveys that were originally collected by the Police Foundation and sponsored by the United States Department of Justice. This data set was released to the public domain by the Interuniversity Consortium for Political and Social Research (ICPSR) in 2008. The response rate for the telephone surveys was approximately $50 \%$, which is considered decent enough for research purposes.

\section{Results and Discussion}

The data in Table 2 show that this fifteen-variable model $^{2}$ explains about $33 \%$ of the variation on gun ownership in the sample. Additionally, this model correctly classified $72 \%$ of the cases, and the Hosmer and Lemeshow's test of goodness-offit was not significant, $\chi^{2}(8, N=1772)=7.087, p=.527$, which indicates adequate model fit for the purpose of data analysis.

To examine what factors predict the likelihood that the respondents would report they own guns, direct logistical regression was performed. The results from the logistic regression in Table 2 show that eleven variables were statistically significant. The strongest predictor of gun ownership was farm-country location of the residency, recording an odds ratio of 3.703. This indicates that the respondents who lived in the farm-country were almost 4 times more likely to own guns compared to all other residency locations, controlling for all other factors in the mode. The second strongest predictor of gun ownership was parent gun ownership status, recording an odds ratio of 2.789. This indicates that if the parents of the respondent owned guns, then they were almost 3 times more likely to own guns compared to respondents who reported their parents did not own guns. This shows that gun ownership is highly influenced by a gun culture in the family. Other influencing factors in favor of gun ownership were being a veteran, $b=.621, p=$ $001, \mathrm{OR}=1.860(95 \% \mathrm{CI}: 1.355,2.554)$, living in a small city $\mathrm{b}=.504, \mathrm{p}=001$, $\mathrm{OR}=1.656$ (95\% CI: 1.259, 2.178), perceived crime level, $\mathrm{b}=.263, \mathrm{p}=05, \mathrm{OR}=$ 1.301 (95\% CI: 1.035, 1.635), higher income, $b=.199, p=001, \mathrm{OR}=1.220(95 \%$ CI: $1.134,1.312$ ), and the number of people in the household, $b=.153, p=05$, OR $=1.165$ (95\% CI: $1.035,1.327)$. On the other hand, factors that had a negative impact on gun ownership were age $(\mathrm{OR}=.981)$, race $(\mathrm{OR}=.412$ for Blacks, and $\mathrm{OR}=.200$ for Hispanics), and a higher number of children in the household (OR = .811). It is widely believed that the political affiliation has a significant effect on gun ownership. Contrary to this popular belief, the data in Table 2 shows that political affiliation is not a significant predictor of gun ownership in the United States.

\footnotetext{
${ }^{2}$ Political affiliation in this study was one variable with three categories. Likewise, location of residency was one variable with four categories. Each category was converted to dichotomous variables, which contributed to an increase in the number of variables in the model to nineteen.
} 
Table 2. Logistic Regression Analysis Predicting Gun Ownership

\begin{tabular}{|c|c|c|c|c|c|c|c|}
\hline \multirow{2}{*}{ Predictors } & \multirow{2}{*}{ B } & \multirow{2}{*}{ S.E. } & \multirow{2}{*}{ Wald } & \multirow{2}{*}{ Sig. } & \multirow{2}{*}{$\operatorname{Exp}(B)$} & \multicolumn{2}{|c|}{ 95\% C.I. for $\operatorname{EXP}(B)$} \\
\hline & & & & & & Lower & Upper \\
\hline Age & -.019 & .005 & 18.240 & .000 & .981 & .972 & .990 \\
\hline Black & -.886 & .158 & 31.359 & .000 & .412 & .302 & .562 \\
\hline Hispanic & -1.610 & .186 & 74.767 & .000 & .200 & .139 & .288 \\
\hline Married & .241 & .132 & 3.314 & .069 & 1.272 & .982 & 1.649 \\
\hline Number of Children & -.209 & .052 & 16.235 & .000 & .811 & .733 & .898 \\
\hline Employment & -.183 & .159 & 1.323 & .250 & .833 & .610 & 1.138 \\
\hline Education & -.057 & .045 & 1.598 & 206 & .945 & .866 & 1.032 \\
\hline Income & 199 & .037 & 28.736 & .000 & 1.220 & 1.134 & 1.312 \\
\hline Veteran Status & .621 & 162 & 14.719 & .000 & 1.860 & 1.355 & 2.554 \\
\hline Parents own Guns & 1.026 & .113 & 81.771 & .000 & 2.789 & 2.233 & 3.483 \\
\hline How Safe in Neighborhood & -.017 & .074 & .054 & .817 & 983 & .850 & 1.137 \\
\hline How Safe at Home & .009 & .092 & .009 & .924 & 1.009 & .842 & 1.209 \\
\hline Perceived Crime Level & .263 & 117 & 5.085 & .024 & 1.301 & 1.035 & 1.635 \\
\hline Number of People in House & .153 & .066 & 5.313 & .021 & 1.165 & 1.023 & 1.327 \\
\hline Farm - Country & 1.309 & .186 & 49.465 & .000 & 3.703 & 2.571 & 5.333 \\
\hline Small City & .504 & .140 & 13.005 & .000 & 1.656 & 1.259 & 2.178 \\
\hline Medium City & .247 & .161 & 2.361 & .124 & 1.280 & .934 & 1.755 \\
\hline Conservative & .205 & .138 & 2.203 & .138 & 1.228 & .936 & 1.610 \\
\hline Moderates & .023 & .148 & .023 & .878 & 1.023 & .766 & 1.367 \\
\hline Constant & -1.336 & .474 & 7.935 & .005 & .263 & ------ & -------- \\
\hline
\end{tabular}

\section{R-Squares}

Cox \& Snell $\mathrm{R}^{2}=.246$

Nagelkerke $\mathrm{R}^{2}=.329$

Note: White race is used as the base comparison. Large City is used as the base comparison for residency (i.e., Farm-Country, Small City, and Medium City all are measured against the base variable). Liberals are the base comparison for political affiliation variables.

The second research question in this study relates to factors that have a statistically significant influence on the decision to buy guns. This question is answered based on the statistical model that is presented in Table 3. The data in Table 3 show that this fifteen-variable model explains $15 \%$ of the variation on the decision to buy guns among participants in the sample. Additionally, this model correctly classified $90.9 \%$ of the cases in the model, and the Hosmer and Lemeshow's test of goodness-of-fit was not significant, $\chi^{2}(8, N=815)=9.786, p=$ .280 , which indicates adequate model fit. 
Table 3. Logistic Regression Analysis of Factors that Influence the Decision to Buy Guns

\begin{tabular}{|l|c|c|c|c|c|c|c|}
\hline \multirow{2}{*}{ Predictors } & \multirow{2}{*}{ B } & \multirow{2}{*}{ S.E. } & \multirow{2}{*}{ Wald } & \multirow{2}{*}{ Sig. } & \multirow{2}{*}{ Exp(B) } & \multicolumn{3}{|c|}{ 55\% CI for EXP(B) } \\
\hline Age & -.025 & .010 & 5.588 & $\mathbf{. 0 1 8}$ & $\mathbf{. 9 7 6}$ & .956 & .996 \\
\hline Black & .974 & .345 & 7.946 & $\mathbf{. 0 0 5}$ & $\mathbf{2 . 6 4 7}$ & 1.345 & 5.210 \\
\hline Hispanic & .799 & .362 & 4.873 & $\mathbf{. 0 2 7}$ & $\mathbf{2 . 2 2 4}$ & 1.094 & 4.523 \\
\hline Married & .354 & .303 & 1.367 & .242 & 1.425 & .787 & 2.578 \\
\hline Number of Children & -.098 & .106 & .852 & .356 & .907 & .736 & 1.116 \\
\hline Employment & -.910 & .334 & 7.435 & $\mathbf{. 0 0 6}$ & $\mathbf{. 4 0 2}$ & .209 & .774 \\
\hline Education & .017 & .109 & .025 & .875 & 1.017 & .822 & 1.259 \\
\hline Income & .074 & .079 & .886 & .347 & 1.077 & .923 & 1.258 \\
\hline Veteran Status & .985 & .387 & 6.492 & $\mathbf{. 0 1 1}$ & $\mathbf{2 . 6 7 9}$ & 1.255 & 5.715 \\
\hline Parents own Guns & .683 & .267 & 6.532 & $\mathbf{. 0 1 1}$ & $\mathbf{1 . 9 8 0}$ & 1.173 & 3.345 \\
\hline How Safe in Neighborhood & .054 & .165 & .108 & .742 & 1.056 & .764 & 1.459 \\
\hline How Safe at Home & .460 & .188 & 5.990 & $\mathbf{. 0 1 4}$ & $\mathbf{1 . 5 8 3}$ & 1.096 & 2.288 \\
\hline Perceived Crime Level & .582 & .255 & 5.217 & $\mathbf{. 0 2 2}$ & $\mathbf{1 . 7 9 0}$ & 1.086 & 2.951 \\
\hline Number of People in House & .057 & .142 & .159 & .690 & 1.059 & .801 & 1.400 \\
\hline Farm - Country & 1.142 & .443 & 6.631 & $\mathbf{. 0 1 0}$ & $\mathbf{3 . 1 3 2}$ & 1.314 & 7.470 \\
\hline Small City & .404 & .342 & 1.395 & .237 & 1.497 & .766 & 2.925 \\
\hline Medium City & .056 & .360 & .024 & .876 & 1.058 & .522 & 2.144 \\
\hline Conservative & .418 & .313 & 1.776 & .183 & 1.518 & .822 & 2.806 \\
\hline Moderates & -.124 & .379 & .107 & .744 & .884 & .421 & 1.856 \\
\hline Constant & -4.794 & 1.085 & 19.525 & .000 & .008 & ----- & ----- \\
\hline R-Squares & & & & & & & \\
\hline Nox \& Snell R ${ }^{2}=.068$ & & & & & & & \\
\hline Nogelkerke R ${ }^{2}=.150$ & & & & & & \\
\hline
\end{tabular}

Note: White race is used as the base comparison. Large City is used as the base comparison for residency (i.e., Farm-Country, Small City, and Medium City all are measured against the base variable). Liberals are the base comparison for political affiliation variables.

The results from the logistic analysis in Table 3 show that nine variables were statistically significant. Seven out of nine significant variables in this model had a positive effect on the decision to buy guns, whereas two of them had a negative effect (i.e., age and employment). The strongest influencing factor was location of residency; specifically, farm-country, recording an odds ratio of 3.132. This means that individuals who live in farm-country are 3 times more likely to think about buying guns compared to other locations (e.g., big cities, medium-size cities, and small cities). The second strongest influencing factor was veteran status, recording an odds ratio of 2.679 , followed by the race factor. Both blacks, $b=.974, p=01$, $\mathrm{OR}=2.647$ (95\% CI: 1.345, 5.210), and Hispanics, $\mathrm{b}=.799, \mathrm{p}=05, \mathrm{OR}=2.224$ (95\% CI: 1.094, 4.523), were over 2 times more likely "Yes" they are willing to buy guns compared to whites. This doesn't mean that blacks and Hispanics own 
more guns than whites. It only means that blacks and Hispanics are more willing to buy guns. Whites own more guns than any other races, and this question is answered from the data on Table 2 above - in reference to the first research question. Other significant factors include parent's gun ownership status (OR = $1.980)$, perceived crime level in the neighborhood $(\mathrm{OR}=1.790)$, and the safety concern at home $(\mathrm{OR}=1.583)$. The two factors that have a negative impact on the decision to buy guns are age $(\mathrm{OR}=.976)$ and employment $(\mathrm{OR}=.402)$. This means that older people and those who are employed are less likely to buy guns compared to younger people and those who are unemployed. In other words, for every year increase in age, the odds of buying guns decrease by a factor of .976 . Likewise for employment; as the employment status changes from being unemployed (coded 0 ) to employed (coded 1), the odds of willingness to buy guns decrease by a factor of .402 , holding all other variables constant.

The data in Table 4 answer the question: why do people buy or own guns in the United States? Before addressing this question, it is important to note that most people refused to answer this question either directly or offered no response at all, as shown on Table 4 below. Furthermore, the answer to research question three relies on a usable sample of 576 responses, which is still considered a large sample. The data in Table 4 show that the primary reason for owning guns is for hunting. Self-defense comes second on the list, and owning guns for sports is ranked third on the same list. Surprisingly, the right to bear arms as a Constitutional right is one of the lowest on the list, with only .2\%. Nonetheless, the right to bear arms under the United States Constitution is what give people the freedom to own guns in the first place.

Table 4. Descriptive Statistics: Reasons for Owning Guns

\begin{tabular}{|l|c|c|c|}
\hline Reasons for Owning Guns & Frequency & Percent & Cumulative Percent \\
\hline Self-defense & $\mathbf{7 0}$ & $\mathbf{2 . 7 \%}$ & $\mathbf{2 . 7 \%}$ \\
\hline Hunting & $\mathbf{3 8 6}$ & $\mathbf{1 5 . 0 \%}$ & $\mathbf{1 7 . 8 \%}$ \\
\hline Sport/target practicing & $\mathbf{4 6}$ & $\mathbf{1 . 8 \%}$ & $\mathbf{1 9 . 5 \%}$ \\
\hline Collector & 8 & $.3 \%$ & $19.9 \%$ \\
\hline Job related & 5 & $.2 \%$ & $20.1 \%$ \\
\hline Like guns & 22 & $.9 \%$ & $20.9 \%$ \\
\hline Inherited it & 10 & $.4 \%$ & $21.3 \%$ \\
\hline It was a gift & 12 & $.5 \%$ & $21.8 \%$ \\
\hline Right to bear arms & $\mathbf{5}$ & $\mathbf{. 2 \%}$ & $\mathbf{2 2 . 0 \%}$ \\
\hline Kill small animals & 5 & $.2 \%$ & $22.2 \%$ \\
\hline Don't know & 7 & $.3 \%$ & $22.4 \%$ \\
\hline Refused & 1 & $.01 \%$ & $22.5 \%$ \\
\hline Unknown & 1991 & $77.5 \%$ & $100.0 \%$ \\
\hline Total & 2568 & $100.0 \%$ & \\
\hline
\end{tabular}

One of the most intriguing questions that people ask around the globe is how 
many firearms do Americans have in a typical household. The present study attempts to answer this question inferentially, using a sample of 317 household participants. The household participants were asked to self-report whether they have more than 10 firearms, 6 to 10 firearms, 1 to 5 firearms, or no firearms at all. The data in Table 5 show that $42.5 \%$ of household participants reported having more than 10 guns in their homes. Of the 317 household participants in the sample, $28.7 \%$ reported having 6 to 10 firearms, $18.9 \%$ reported having 1 to 5 firearms, and only $9.7 \%$ of them reported having no firearms in their homes. To summarize, $90.3 \%$ of all household participants in the sample reported having at least one firearm in their home. Overall, $71.2 \%$ of all household participants reported having multiple firearms (6 or more) in their homes.

Table 5. The Number of Self-Reported Firearms in Households $(N=317)$

\begin{tabular}{|l|c|c|c|}
\hline $\begin{array}{l}\text { Number of reported } \\
\text { gun }\end{array}$ & Frequency & Percent & Cumulative Percent \\
\hline More than 10 firearms & 135 & $\mathbf{4 2 . 5 \%}$ & $42.5 \%$ \\
\hline 6 to 10 firearms & 91 & $28.7 \%$ & $71.2 \%$ \\
\hline 1 to 5 firearms & 60 & $18.9 \%$ & $90.1 \%$ \\
\hline 0 firearms & 31 & $\mathbf{9 . 7 \%}$ & $100.0 \%$ \\
\hline Total & 317 & $100.0 \%$ & \\
\hline
\end{tabular}

Note: Each cumulative percent is rounded up.

\section{Conclusions}

People buy and own guns for varying reasons, but a growing trend finds protection to be the number one rationale (Parker et al. 2017, Homenway and Solnick 2015, Southwick 2000, Kleck and Gertz 1998, Bryant and Shoemaker, 1988). For a person, the ability to protect his family, house/belongs, and property in the event of an emergency remains a Constitutional right of every American citizen. It is noteworthy that a significant contributing factor of gun ownership is the media. The media/news inflates individual's perception regarding the amount of and the type of violence that occurs in our nation; thus making citizens believe they need to do something to protect themselves to feel safe (Dowler 2002, Cohen et al. 2012). Another concern people have is the inability of law enforcement to swiftly react and handle situations where safety is at stake, which means relying on self-help (McDowall and Loftin 1983). This further strengthens the belief that citizens should be able to defend themselves in such situations. Nonetheless, the current study does not fully concur with prior research in this regard. This study shows that the primary reason for owning guns is for hunting. Self-defense comes second on the list, and owning guns for sports/target practicing is ranked third on the same list.

Gun ownership is a hot topic in the United State, and with every hot topic of this magnitude, there are always two sides of the story. There are those who support and those who oppose it, and both sides have legitimate reasons to hold such beliefs. However, gun ownership in the United States is a constitutional right, and most likely it will not go away, which makes it an on-going debate. This 
doesn't mean that people buy or own firearms just because it is a constitutional right; it means that this right is protected by the U.S. Constitution. In fact, the results of the current study show that the right to bear arms as a Constitutional right is one of the lowest on the list of reasons for owning guns, with only .2\% (see Table 4). The current research doesn't support the idea that people in the United States own or buy guns just because it is a constitutional right. On the other hand, those who oppose gun ownership have several legitimate concerns about who should own firearms, and whether these individuals are properly instructed on use and safety practices. The question of "who" can own guns is indeed a major concern; especially when dealing with persons who have personality disorders and are mentally unstable. In specific instances, mentally unstable people are more likely to get involved in mass shootings such as that of Stephen Paddock in Las Vegas shooting case, James Holmes in the Colorado movie theater, the Sandy Hook Elementary shooting in Newtown, Connecticut, and more recently Charleston church shooting in South Carolina (DeFoster and Swalve 2017, Krouse and Richardson 2015, Metzl and MacLeish 2015). Unfortunately, those cases reach the attention of law enforcement after the fact, and in most cases, persons involved in those mass shootings are undiagnosed with mental illness.

One of the most interesting findings of the current study is the relationship between political affiliation and gun ownership. It is widely believed that the political affiliation has a significant effect on gun ownership (Parker et al. 2017, Spitzer 2014, Bruce and Wilcox 1998). Contrary to this popular belief, the findings of this study show that political affiliation is not a significant predictor of gun ownership in the United States. The current study shows that the environmental factors (e.g., location of residency) and psychosocial factors (e.g., fear of crime and safety concerns) are significant predictors of gun ownership. This study shows that the strongest predictor of gun ownership was farm-country location of the residency, indicating that the respondents who lived in the farmcountry were almost 4 times more likely to own guns compared to other residency locations (e.g., large cities). The second strongest predictor of gun ownership was parents gun ownership status, indicating that if the parents of the respondents owned guns, then they were almost 3 times more likely to own guns and 2 times more likely to buy guns compared to respondents who reported their parents did not own guns. This shows that gun ownership is highly influenced by a gun culture in the family (Lizotte et al. 1981). Additionally, having a higher income and the status of a veteran both had a significant and positive correlation with gun ownership, followed by the perceived level of crime and home safety, which is consistent with other studies (Spano and Bolland 2010, Holbert et al. 2004, Vacha and McLaughlin 2000).

The current study also examined specific factors that have a statistically significant influence on the decision to buy guns. In this regard, the strongest influencing factor was location of residency; specifically, farm-country, followed by the veteran status and respondents' race. Regarding race as an influencing factor, this study reveals two interesting findings: 1) whites own more guns than blacks and Hispanics (see Table 2, white race is the base category); but 2) blacks and Hispanics are more willing to buy guns than whites (see Table 3), which 
contradicts that reality of actual gun ownership.

The fourth and most interesting research question that this study addresses is: How many firearms do each household have in the United States? As stated in the results section, this question can only be answered inferentially by taking into account the results from a sample of 327 household participants. The results of this study show that $90.3 \%$ of all household participants in the sample reported having at least one firearm in their homes, and $71.2 \%$ of all household participants reported having multiple firearms ( 6 or more) in their homes. Perhaps the answer to this question makes this study unique in its nature, and one of the first studies to address this question from the research perspective.

In conclusion, gun ownership in America runs in the family. Additionally, people do not own guns just because they are affiliated with a certain political party, or solely based on fear of crime or victimization. Fear of crime or victimization is just a partial explanation of gun ownership. Instead, gun ownership is more related to "aggressive attitudes...[which] symbolize 'fundamental questions about the ....social system"' (as cited in Williams and McGrath 1976: 22), which remains an open topic for future research. The idea that one political party uses gun-rights to gain a higher status to prevent the other political party from becoming more politically powerful (Hofstadter and Wallace 1971) is also an outdated belief system. Gun ownership is mainly affected by the social system, the pro-guns values embedded in the culture in particular (Kalesan et al. 2016, Cao et al. 2006). Gun ownership is a psychosocial factor in itself. Unfortunately, gun ownership comes with a high cost when considering gun violence, but it strengthen the mentality of people by feeding the attitudes of superiority. In other words, you cannot win unless you believe that you can do it. Likewise, you cannot maintain a strategic dominance in the world if you don't believe that you can and are entitled to do so. Furthermore, one cannot maintain the true sovereignty of a country unless believing in a true or segmented superiority, and that form of superiority or mentality is cultivated by a culture that puts value on gun ownership.

\section{References}

Bruce J M, Wilcox C (1998) The Changing Politics on Gun Control. New York, NY: Rowman \& Littlefield Publishers, Inc.

Bryant CD, Shoemaker DJ (1988) Gun Ownership and Carrying. Psychological Reports, 62: 61-62.

Callahan CM, Rivara FP (1992) Urban High School Youth and Handguns: A Schoolbased Survey. JAMA 167(22): 3038-3042.

Cao L, Cullen FT, Link BG (2006) The Social Determinants of Gun Ownership: Selfprotection in an Urban Environment. Criminology 35(4): 629-659.

Chemerinsky E (2004) Putting the Gun Control Debate in Social Perspective. Fordham Law Review 73(2): 477-485.

Cohen EL, Fujioka Y, Hoffner C (2012) Exploring Gun Ownership as a Social Identity to Understanding the Perceived Media Influence of Virginia Tech News Coverage on Attitudes Toward Gun Control Policy. Journal of Communication Research Reports 29(2): 130-39. 
Cook PJ, Harris RJ, Ludwig J, Pallack HA (2015) Some Sources of Crime Guns in Chicago: Dirty Dealers, Straw Purchasers, and Traffickers. Journal of Criminal Law \& Criminology 104(4): 717-760.

David WC (1997) Government of our Own: The Making of Confederacy. Baton Rouge, LA: Louisiana State University Press.

DeFoster R, Swalve N (2017) Guns, Culture or Mental Health? Framing Mass Shooting as a Public Health Crisis. Health Communication 33(10): 1211-1222.

Doherty J (1988) Psychological Morale: Its Conceptualization and Measurement. The Doherty Inventory of Psychological Moral (DIPM). Educational Studies 14(1): 6575.

Dowler K (2002) Media Influend on Attitudes toward Guns and Gun Control. American Journal of criminal Justice 26(2): 235-257).

Gilson D (2013) 10 Pro-gun Myths, Shot Down. Mother Jones, Nonprofit Independent journalism. Retrieved from https://bit.ly/2F4h5oY.

Hauser W, Kleck G (2013) Guns and Fear: A One-way Street? Crime \& Delinquency 59(2): 271-291.

Hemenway D (2013) Preventing Gun Violence by Changing Social Norms. JAMA Internal Medicine 174(13): 1167-1168.

Hemonway D, Miller AM (2000) Gun use in the United States: Results from Two National Surveys. Injury Prevention 6(4): 263-267.

Hemonway D, Miller AM (2006) Is an Armed Society a Polite Society? Guns and Road Rage. Accident Analysis and Prevention 38(4): 687-695.

Hemenway D, Prothrow-Stith D, Bergstein JM, Ander R, Kennedy BP (1996) Gun carrying among adolescents. Journal of Contemporary Problems 59(1): 39-53.

Hemenway D, Solnick SJ (2015). The epidemiology of self-defense gun use: Evidence from the national crime victimization surveys 2007-2011. Preventive Medicine 79: 22-27.

Hofstadter R, Wallace M (Eds) (1971) American Violence: A documentary history. New York, NY: Alfred A Knopf.

Holbert LR, Shah DV, Kwak N (2004) Fear, Authority, and Justice: Crime-related TV Viewing and Endorsements of Capital Punishment and Gun Ownership. Journalism \& Mass Communication Quarterly 81(2): 343-363.

Jemal A, Ward E, Hao Y (2005) Trens in the leading causes of Death in the United States, 1970-2002. JAMA 294(10): 1255-1259.

Jiobu RM, Curry RJ (2001) Lack of Confidence in the Federal Government and the Ownership of Firearms. Social Science Quarterly 82(1): 77-88.

JUSTIA (2018) Self-defense and Defense of others. Retrieved from https://bit.ly/2FoE3Hd.

Kalesan B, Villarrear MD, Keyes KM, Galea S (2016) Gun Ownership and Social Gun Culture. Injury Prevention 22(3): 1-5.

Kennedy DM, Piehl AM, Braga AA (1996). Youth Violence in Boston: Gun Markets, Serious Youth Offenders, and a Use-reduction Strategy. Law and Contemporary Problems 59(1): 147-196.

Kleck G, Gertz M (1998) Carrying Guns for Protection: Results from the National Selfdefense Survey. Journal of Research in Crime and Delinquency 35(2): 193-224.

Kleck G, Kovandzic T, Saber M, Hauser W (2011) The Effect of Perceived Risk and Victiminsation on Plans to Purchase a Gun for Self-protection. Journal of Criminal Justice 39(4): 312-319.

Kochanek KD, Murphy SL, Xu J (2015) Deaths: Final data for 2011. National Vital Statistics Report 63(3): 1-120.

Krouse WJ, Richardson DJ (2015) Mass Murder with Firearms: Incidents and Victims 
1999-2013. Congressional Research Service. Retrieved from https://bit.ly/2D2jHSB.

Lizotte AJ, Bordua DJ, White CS (1981) Firearms Ownership for Sport and Protection: Two not so Divergent Models. American Sociological Review 46(4): 499-503.

Mokdad AH, Marks JS, Stroup DF (2004) Actual Causes of Death in the United States, 2000. JAMA 291(10): 1238-1245.

McDowall D, Loftin C (1983) Collective Security and Demand for Legal Handguns. American Journal of Sociology 88(6): 1146-1161.

Morgan ER, Rahbar AR, Azrael D, Miller M (2018) Public Perceptions of Firearm and Non-firearm related Death in the United States: A National Survey. Annals of Internal Medicine 169(10): 734-737.

Menard SW (2002) Applied Logistic Regression ( $2^{\text {nd }}$ ed.). Thousand Oaks, CA: SAGE Publications.

Metzl JM, MacLeish KT (2015) Mental Illness, Mass Shooting, and the Politics of American Firearms. American Journal of Public Health 105(2): 240-149.

Miller M, Azrael D, Hepburn L, Hemenway D, Lippmann SJ (2006) The Association between Change in Household Firearm Ownership and Rates of Suicide in the United States. Injury Prevention 12: 178-182.

O’Brien K, Forrest W, Lynott D, Daly M (2013) Racism, Gun Ownership and Gun Control: Biased Attitudes in US whites may Influence Policy Decisions. PLoS ONE 8(10): $1-9$.

Pallant J (2007) SPSS: Survival manual ( $3^{\text {rd }}$ ed). Two Penn Plaza, New York, NY: Open University Press.

Papachristos AV, Meares TL, Fagon J (2012) Why do Criminals Obey the Law? The Influence of Legitimacy and Social Networks on Active Gun Offenders. Journal of Criminal Law and Criminology 102(2): 397-440.

Parker K, Horowitz MJ, Igielnik R, Oliphant B, Brown A (2017) The Demographics of Gun Ownership. Pew Research Center. Retrieved from https://pewrsr.ch/2QBxz9L.

Pew Research Center (2013) Why own a Gun? Protection is now Top Reason. Retrieved from https://pewrsr.ch/1GElmIr.

Saad L (2011) Self-reported Gun Ownership in U.S. is Highest since 1993. Gallup. Retrieved from https://bit.ly/1bynZf6.

Southern Poverty Law Center (2014) Intelligence Report: Active Patriot Groups in the United States in 2013. Retrieved from https://bit.ly/2VK8xtc.

Southwick L Jr. (2000) Self-defense with Guns: The Consequences. Journal of Criminal Justice 28(5): 351-370.

Spano R, Bolland J (2010) Disentangling the Effects of Violent Victimization, Violent Behavior, and Gun Carrying for Minority Inner-city Youth Living in Extreme Poverty. Crime \& Delinquency 59(2): 191-213.

Spitzer RJ (2014) Politics of Gun Control. New York, NY: Routledge Publishing.

Vacha EF, McLaughlin TF (2000) The Impact of Poverty, Fear of Crime, and Crime Victimization on Keeping Firearms for Protection and Unsafe Gun-storage Practices: A Review and Analysis of Policy Recommendations. Urban Education 35(4): 496510.

Van Kesteren J (2014) Revisiting the Gun Ownership and Violence Link: A Multi-level Analysis of Victimization Survey Data. British Journal of Criminology, Delinquency and Deviant Social Behavior 54: 53-72.

Violence Policy Center (2013) When Mend Murder Woman: An Analysis of 2013 Homicide Data. Retrieved from https://bit.ly/2FjnbST.

William JS, McGrath JH III (1976) Why people own guns? Journal of Communication 26(4): 22-30.

Swanson JW, Sampson NA, Petukhova MV, Zaslavsky AM, Applebaum PS, Swartz MS, 
Vol. 6, No. 3 Avdija: The Psychosocial Ecology of Gun Ownership in the...

Kessler RC (2015) Guns, Impulsive Angry Behavior, and Mental Disorders: Results from the National Comorbidity Survey Replication. Behavioral Sciences and the Law 23(2-3): 199-212. 